\title{
Enhanced insulation temperature and the reduced thermal conductivity of nanostructured ceramic coating systems
}

\author{
L.H. Liang ${ }^{\mathrm{a}, *}$, H. Wei ${ }^{\mathrm{b}}$, X.C. Chang ${ }^{\mathrm{b}}$, W. Xu ${ }^{\mathrm{a}}$, X.N. Li ${ }^{\mathrm{a}}$, Y.G. Wei ${ }^{\mathrm{a}}$ \\ ${ }^{a}$ LNM, Institute of Mechanics, Chinese Academy of Sciences, Beijing 100190, China \\ ${ }^{\mathrm{b}}$ Institute of Metal Research, Chinese Academy of Sciences, Shenyang 110016, China
}

\section{A R T I C L E I N F O}

\section{Article history:}

Received 30 March 2012

Received in revised form 11 April 2013

Accepted 4 June 2013

Available online 2 July 2013

\section{Keywords:}

Nanoparticles

Thermal conductivity

Size effect

Insulation temperature

\begin{abstract}
A B S T R A C T
The theoretical model on the size-dependent thermal conductivity of the nanograins and the composites, based on the phonon confinement and the boundary scattering effects, was developed to predict the $68 \%$ reduced thermal conductivity of the nanostructured ceramic coatings made of grains of $40-100 \mathrm{~nm}$ compared with the conventional ceramic coatings with micron-scale grains. In order to validate the model, the nanostructured zirconia layers and the corresponding conventional layers were sprayed on the same alloy matrixes, and the insulation temperatures were measured at different temperatures up to $1273 \mathrm{~K}$. It was found that insulation temperature of the nanostructured ceramic systems enhanced about $200 \mathrm{~K}$ at most compared with that of the conventional ones. And the average enhancement of the insulation effect is in agreement with the theoretical prediction. The nanostructured ceramic coated systems provide the extending application in thermal barrier engineering, thermoelectric devices and other related applications.
\end{abstract}

(c) 2013 Elsevier Ltd. All rights reserved.

\section{Introduction}

The low thermal conductivity is one of important properties for thermal barrier engineering and thermoelectric devices, etc. The thermal barrier coatings, made of the $\mathrm{Y}_{2} \mathrm{O}_{3}$ stabilized $\mathrm{ZrO}_{2}$ ceramics, are used to provide thermal insulation to the interior metallic components from the hot gas stream in gas turbine engines for aircraft propulsion, power generation, and marine propulsion [1-3]. The use of ceramic top layers, with $100-500 \mu \mathrm{m}$ thickness, provides major reduction in the surface temperature $(100-300 \mathrm{~K})$ of the metallic alloy and makes engine components more durable [2]. The air-plasma-sprayed ceramic layers, with the conventional splat grains in micron-scale, have the low thermal conductivity of about $2 \mathrm{~W} \mathrm{~m}^{-1} \mathrm{~K}^{-1}$ [1]. However, how to reduce the thermal conductivity further and enhance actually the thermal protection efficiency at the given layer thickness, for more exacting application, is still challenge. In order to obtain the lower thermal conductivity of the ceramics, the effort has been paid out by changing the density, the microstructure scale, or the component of the ceramics $[4,5]$. Although there were reports of the reduced thermal conductivity of nanostructured ceramic layers, the increase of the porosity was as the cost [5], which may affect the mechanical properties of the systems. The study has indicated that the scattering effect of surface or grain boundary can decrease the conductivity

\footnotetext{
* Corresponding author. Tel.: +86 1082543972.

E-mail address: lianglh@Inm.imech.ac.cn (L.H. Liang).
}

for nanocrystals [6,7]. However, the nanoscale polycrystalline structures, prepared by other method, even showed the higher thermal conductivity [4]. Moreover, the obviously enhanced insulation temperature of the nanostructured ceramic coated systems was few reported. Is the thermal protection effect of the nanostructured ceramic systems indeed better? And what's the underlying physical mechanism? A quantitative theory of reducing thermal conductivity and enhancing insulation temperature, with determinate parameters, is desired not only in engineering application, but also in scientific understanding.

In this paper, the theoretical model on the reduced thermal conductivity of the nanograins and the composites was developed, and the enhanced insulation temperature was predicted. According to the model, the thermal protection effect of the nanostructured and the conventional ceramic coated alloy samples were studied comparatively by measuring the insulation temperature difference between two kinds of samples at the same time at a series of temperatures. The obviously enhanced insulation temperature of the nanostructured ceramic samples was found, and the experimental result agrees with the theoretical prediction.

\section{Theoretical model}

According to the kinetic formula of the thermal conductivity $k=1 / 3 C v l$, where $C$ is the specific heat, $v$ is the average phonon velocity, and $l$ is the phonon mean free path, considering the phonon confinement and the boundary scattering effect induced by 


\begin{tabular}{|c|c|c|c|}
\hline \multicolumn{4}{|c|}{ Nomenclature } \\
\hline$k$ & thermal conductivity & \multirow[t]{2}{*}{$T_{S}$} & \multirow{2}{*}{$\begin{array}{l}\text { surface temperature of matrix of the matrix/coat sam- } \\
\text { ples }\end{array}$} \\
\hline C & specific heat of crystals & & \\
\hline$v$ & phonon velocity & $q$ & heat flow density per unit time through the surface of \\
\hline$l$ & phonon mean free math & & the samples \\
\hline$p$ & $\begin{array}{l}\text { interface roughness scattering coefficient of nanoparti- } \\
\text { cles }\end{array}$ & $\Delta T$ & $\begin{array}{l}\text { temperature gradient along thickness of the samples, } \\
\text { i.e., the insulation temperature }\end{array}$ \\
\hline$\eta$ & interface rough thickness & $L$ & thickness \\
\hline$D$ & diameter of nanoparticles & $r$ & thermal resistance \\
\hline$l_{0}$ & phonon mean free path of crystals in Debye model & $G$ & thermal conduction \\
\hline$\beta$ & atomic vibration parameter of crystals & $f$ & porosity of the coats \\
\hline$S$ & vibration part of melting entropy & \multicolumn{2}{|c|}{ Subscripts } \\
\hline$H$ & melting enthalpy & $n$ & nanoparticles \\
\hline$T_{0}$ & melting temperature & $b$ & the bulk materials \\
\hline$R$ & ideal gas constant & 1 & the samples coated with nanostructured ceramics \\
\hline$D_{0}$ & minimum critical size of crystals & 2 & the samples coated with conventional ceramics \\
\hline$h$ & atomic diameter & 3 & the samples without ceramic coats \\
\hline$\alpha$ & the factor related to the roughness scattering coefficient & $c$ & the ceramic coat \\
\hline & $p$ & $m$ & the alloy matrix \\
\hline$T_{f}$ & $\begin{array}{l}\text { furnace temperature, i.e., surface temperature of cera- } \\
\text { mic coat of the matrix/coat samples }\end{array}$ & $a$ & the air \\
\hline
\end{tabular}

the small size and the large surface ratio, the thermal conductivity $k_{n}$ of single crystal nanowires, thin films and nanoparticles has been derived by introducing the intrinsic size effect of $v$ and $l$ and combining with the surface scattering effect [6]. $k_{n}$ is expressed as

$K_{n} / k_{b}=\exp \left(-l_{0} / D\right)\left\{\exp \left[(1-\beta) /\left(D / D_{0}-1\right)\right]\right\}^{3 / 2}$,

where $k_{b}$ is the corresponding bulk value, $0<p=1-10 \eta / D \leqslant 1$ is the surface roughness coefficient reflecting the scattering degree, $\eta$ is the surface rough thickness, $D$ is the diameter of the nanowires or the nanoparticles, or the thickness of the thin films, $l_{0}$ is the phonon mean free path of the crystals in the Debye model, $\beta=2 S$ / $(3 R)+1$ is the atomic vibration parameter with the ideal gas constant $R$ and the vibration part of the melting entropy $S=H / T_{0}, H$ is the melting enthalpy of the crystals and $T_{0}$ is the melting temperature, $D_{0}=2 h, 4 h, 6 h$ is the minimum critical size of the thin films, the nanowires, and the nanoparticles, respectively, $h$ is the atomic diameter of the crystals [6]. Equation (1) indicates that the thermal conductivity of the nanowires and the nanoparticles decreases with reducing diameter. The experimental and the simulation study has indicated that the thermal conductivity of single-crystal nanowires and thin films is much lower than the corresponding bulk values [8,9], and Eq. (1) has been validated by the molecular dynamic simulation and the experimental results $[6,8,9]$. The similar trend is estimated for ceramic nanoparticles or nanostructured ceramic layers.

For nano-ceramic layers made of nanoscale grains, Eq. (1) is assuming to be still valid, differently, $D$ is the diameter of the grains, and $D_{0}=6 \mathrm{~h}$ is the minimum critical size of the grains considering that the critical size depends on the dimension [10], $p$ is the interface roughness coefficient among the grains, and $\eta$ is the interface rough (grain boundary) thickness considering that the mechanism of the interface effect is similar to that of the surface effect [7]. Note that the surface scattering effect is neglected since the nano-layers have the same thickness, of several hundreds of microns, as that of the conventional layers with micron-scale

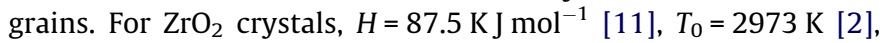
thus $S=29.4 \mathrm{~J} \mathrm{~mol}^{-1} \mathrm{~K}^{-1}$ and $\beta=3.36, h=0.4 \mathrm{~nm}$ (calculated by the atomic volume [12]) and $D_{0}=2.4 \mathrm{~nm}, l_{0}=18.8 \mathrm{~nm}$ (calculated value based on the bulk thermal conductivity, the specific heat, and the phonon velocity related to the elastic modulus and the density [13]). Equation (1) indicates the thermal conductivity $k_{n}$ of the nano-layers will decrease with reducing grain diameter $D$. When $D \rightarrow$ the bulk and $p \rightarrow 1, k_{n} \rightarrow k_{b}$. When $D \rightarrow D_{0}$ or $p \rightarrow 0$, $k_{n} \rightarrow 0$. If the grain size is in the nanoscale range, e.g., $D=(40-$ $100) \mathrm{nm}$, this is possible based on the present technical condition, $k_{n} / k_{b}=(0.5-0.76) p$ in terms of Eq. (1), which indicates that the thermal conductivity of the nano-ceramics can reduce $24-50 \%$, even $p=1$, compared with that of the conventional ones due to the small size and the phonon confinement effect, and is consistent with the recent result that the thermal conductivity of the nanostructured ceramics reduces about $40 \%$ [5].

Considering the increased interface ratio and the boundary scattering effect, the thermal conductivity of the nano-layers can decrease further. In fact, the surface/interface plays an important role in nanoscale heat transport [14]. According to $p=1-\alpha \eta / D$ [6], where $\alpha$ is the factor related to the roughness scattering coefficient, $\alpha=10$ for the surface scattering of the single crystals [6], here $\alpha=10 \times\left(\gamma_{g b} / \gamma_{s v}\right)$ is assumed for the grain boundary scattering considering the weaker effect of the grain boundary compared

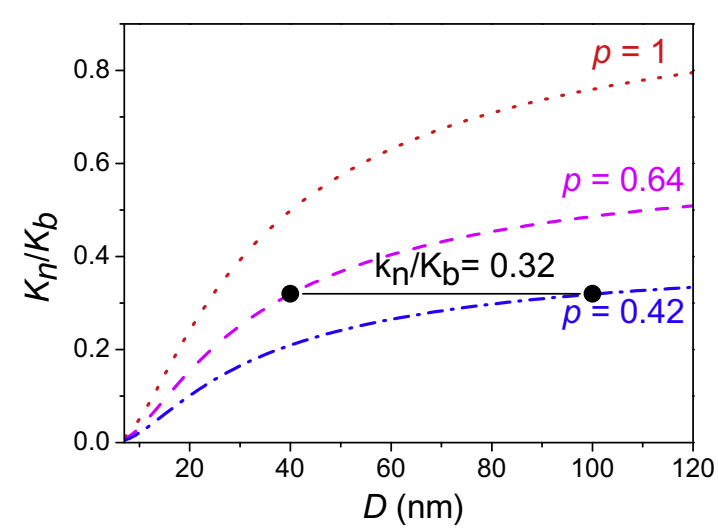

Fig. 1. The thermal conductivity of the nano-ceramics decreases with decreasing grain size and roughness coefficient. 
with that of the surface [7], where $\gamma_{g b}$ and $\gamma_{s v}$ are the grain boundary energy and the surface energy, respectively, and $\gamma_{g b} / \gamma_{s v}=1 / 3$ [7], i.e., $p=1-(10 / 3) \eta / D$. For the grains of $D=(40-100) \mathrm{nm}$, the grain boundary (rough) thickness $\eta=(4.32-17.4) \mathrm{nm}$ is estimated based on the related experimental cognition, this roughness is also reasonable in the fabrication of the nanostructures [8]. Therefore, the interface roughness coefficient $p=1-(10 / 3) \eta / D=(0.64-0.42)$ is predicted, and finally, $k_{n} / k_{b}=(0.5-0.76) p=0.32$ as shown in Fig. 1, which shows the thermal conductivity at the corresponding size and the roughness coefficient. The model predicts that the thermal conductivity of nano-ceramics can reduce about $68 \%$ compared with the conventional ones, which should be related to the corresponding enhancement of the insulation temperatures. In order to validate the theoretical prediction, the nano-samples were prepared and the thermal insulation temperature was measured.

\section{Experimental procedure}

The top surfaces of the alloy specimens with the diameter of $40 \mathrm{~mm}$ and the thickness of $2.8 \mathrm{~mm}$ were coated with the $8 \mathrm{wt} . \%$ $\mathrm{Y}_{2} \mathrm{O}_{3}$ stabilized $\mathrm{ZrO}_{2}$ (YSZ) layers using the standard air plasma spray method [15]. Two kinds of ceramic layers were prepared by the similar process $\left(\mathrm{Ar} / \mathrm{H}_{2}\right)$ on the Metco $7 \mathrm{M}$ atmospheric plasma spray equipment, and the METCO 9MP-DUAL type feedstock system was used. The microstructure of one kind of layers is in nanoscale (the samples are denoted as $S 1$ ) prepared from the nanostructured YSZ powder (CM60, Institute of Process Engineering, Chinese Academy of Sciences), and the other is in micron-scale (S2) prepared from the conventional YSZ powder with the larger granularity (Metco 204CNS, Sulzer Metco, Westbury, NY, USA) by means of the standard parameters suggested by the manufacturer of the powder and torch (Sulzer Metco). The thickness of the both ceramic layers is about $200 \mu \mathrm{m}$, and the morphologies of the both are also similar except the difference of the scale of the grains, the structures will be shown in the next part. The NiCoCrAlY bond layers between the ceramic top layers and the Ni-based superalloy matrixes were prepared using the high velocity oxygen fuel process, and the thickness is about $30 \mu \mathrm{m}$. The total thickness of the coated samples is about $3 \mathrm{~mm}$. The structure of the samples was observed by the FEI Tecnai G2 F20 transmission electron microscope (TEM), the S-570 scanning electron microscope (SEM), and the Neophot21 incident-light microscope.

In order to test the thermal insulation temperature, the two kinds of samples ( $S 1$ and $S 2$ ) were placed in the stokehole of the KSW5-12 box resistance furnace at the same time and fixed on the furnace door, with the ceramic layers facing toward the hearth and the alloy matrixes exposing to the air, i.e., the heat flux is along the direction of the thickness of the samples, the thermocouple of controlling temperature of the resistance furnace was placed on the surface of the ceramic layers. The furnace were heated to $773 \mathrm{~K}, 873 \mathrm{~K}, 973 \mathrm{~K}, 1073 \mathrm{~K}, 1173 \mathrm{~K}, 1273 \mathrm{~K}$, respectively, and then held at each temperature for about $20 \mathrm{~min}$. The surface temperatures of the ceramic layers of the two samples (the same, i.e., the furnace temperatures $T_{f}$ ) were recorded every $30 \mathrm{~s}$. The corresponding matrix temperatures of the two samples $T_{S 1}$ and $T_{S 2}$ were also measured simultaneously by the UJ36a DC potentiometer to compare their thermal insulation effect. Moreover, the samples without the ceramic coats $(S 3)$ were also prepared and $T_{S 3}$ was also measured to demonstrate the thermal insulation effect of the ceramic layers.

\section{Results and discussion}

Fig. 2(a)-(c) shows the cross-section structure of the samples, the surface morphology and the microstructure of the nanostruc- tured ceramic layers, respectively. It can be seen from Fig. 2(b) that there is not obvious difference in the morphology between the nano-layers and the conventional ones, the layers include the molten zone of the ceramic powder and the unmolten zone of the agglomerated powder. However, the grain diameter of the nanoceramics is in the range of about $40-100 \mathrm{~nm}$ as shown in Fig. 2(c), consistent with the requirement of the theoretical design, not like the conventional ceramic layers with the micro-scale bulk grains, and the grain boundary thickness is also consistent with the theoretical estimation. Fig. 3 shows the comparison of the thermal insulation effect between $S 1$ and the $S 2$ during heating. It can be seen that the insulation temperatures of the nanostructured ceramic samples enhance about 36-201 $\mathrm{K}\left(T_{S 2}-T_{S 1}\right)$ compared with that of the conventional ones at the series of the furnace temperatures, which can also be found from Table 1 . Table 2 shows the insulation effect of $S 1$ and $S 3$ after holding $20 \mathrm{~min}$ at the given temperatures. The result indicates that the insulation temperature $\left(T_{f}-T_{S 1}\right)$ of the nanostructured samples enhances with increasing temperature, and reaches $159-277 \mathrm{~K}$ corresponding to $773-1273 \mathrm{~K}$, respectively. Fig. 4 shows the enhanced insulation temperature of the nanostructured samples compared with the samples without ceramic coatings during holding temperatures. The insulation temperature increases obviously in $5 \mathrm{~min}$ of the beginning, reaches 32$240 \mathrm{~K}$ at most corresponding to $773-1273 \mathrm{~K}$, respectively, and does not change nearly after $15 \mathrm{~min}$. In a word, the nanostructured ceramic coated samples have indeed the better thermal protection effect.

For $S 1$ (nano) and $S 2$ (conventional), the experimental conditions such as the size of the samples, the thickness of the ceramic layers, the heating temperature, and the heat flux are all same, the different insulation effects are only resulted from the different thermal conductivities of two samples with different structured ceramic layers. According to the Fourier's Law, the heat flux density $q$ per unit time through the surface of the samples is expressed as $q=-k \Delta T / L$ with the thermal conductivity $k$ and the thickness $L$ of the samples [16], $\Delta T$ is the temperature difference along the direction of the thickness (i.e., the insulation temperature), $\Delta T_{i}=$ $T_{S i}-T_{f}$, where $T_{S i}$ is the matrix temperature of the samples with the subscript $i=1,2$ for $S 1$ and $S 2$, respectively, and the ceramic surface temperature is represented by the furnace temperature $T_{f}$. As above mentioned, $q_{1}=q_{2}, L_{1}=L_{2}$, therefore,

$k_{1} / k_{2}=\Delta T_{2} / \Delta T_{1}$,

i.e., the ratio of the thermal conductivity of $S 1$ to that of $S 2$ can be calculated by the inverse of the ratio of their insulation temperatures. The average value of $k_{1} / k_{2}$ is 0.34 as shown in Table 2, i.e., the insulation temperature of the nano-samples enhances $66 \%$. The value is almost in agreement with the theoretical prediction of $k_{n} / k_{b}=0.32$ based on Eq. (1), the further analysis was carried out combining with the effect of the alloy matrix and the porosity as following.

According to the parallel model of the effective thermal conductivity of the composites including the ceramic layers and the alloy matrixes [17], the effective thermal resistance $r$, vertical to the direction of the heat flux, can be expressed $r=r_{c}+r_{m}$ with the subscripts $c$ and $m$ representing the ceramics and the matrixes, respectively. The above equation can also be expressed as $1 / G=1 / G_{c}+1 /$ $G_{m}$ with the thermal conductance $G=1 / r$ [18]. Considering that $k=G L$ with the Kapitza length being taken as the thickness $L$ [18], there is $L / k=L_{c} / k_{c}+L_{m} / k_{m}$, where $L=L_{c}+L_{m}=3 \mathrm{~mm}$ is the total thickness of the samples, $L_{c}=0.2 \mathrm{~mm}$ is the thickness of the ceramic layers, and $L_{m}=2.8 \mathrm{~mm}$ is the thickness of the matrixes. Therefore, the effective thermal conductivity $k$ of the samples is

$k=L k_{c} k_{m} /\left(L_{c} k_{m}+L_{m} k_{c}\right)$, 
(a)

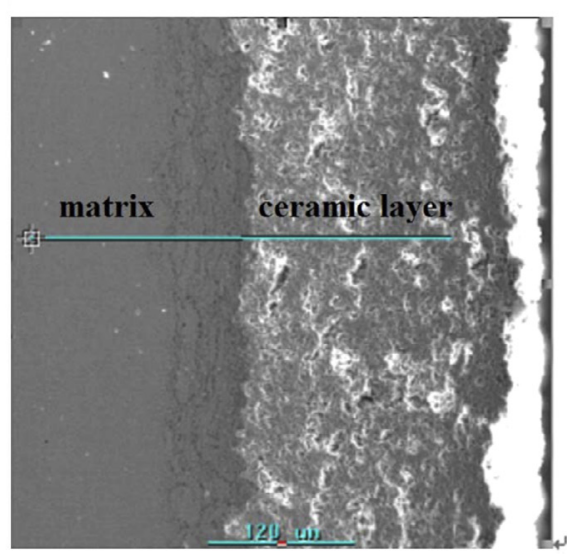

(b)

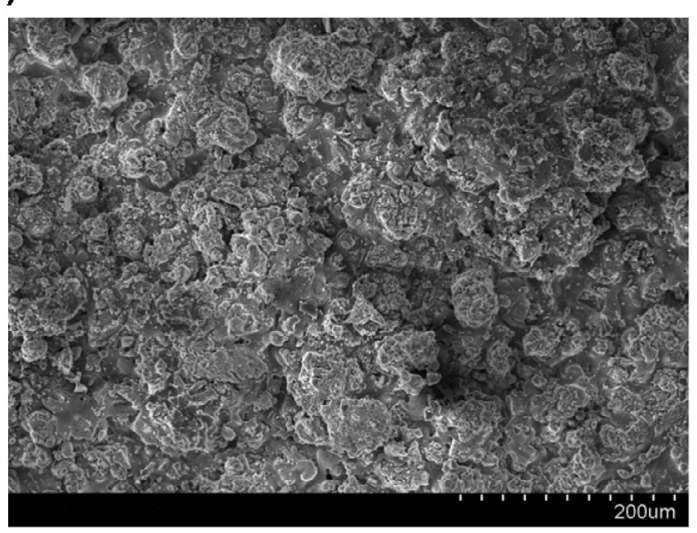

(c)

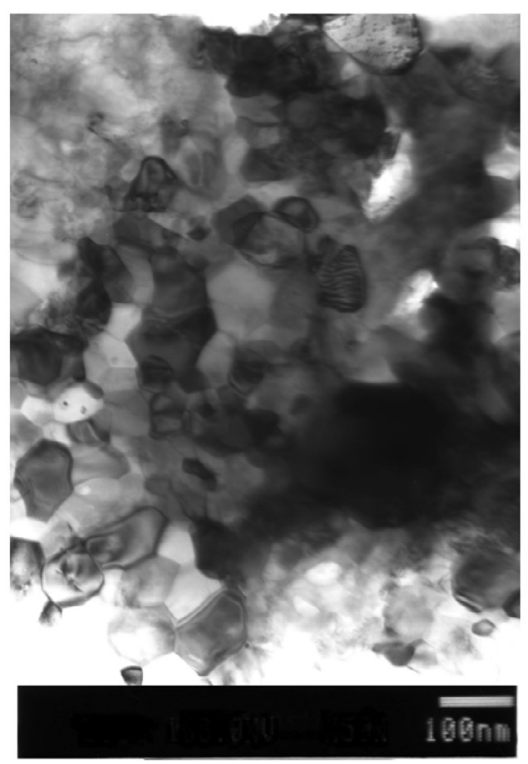

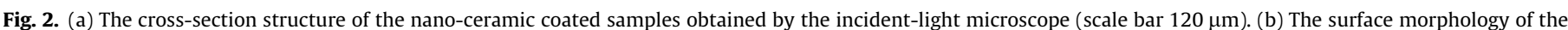

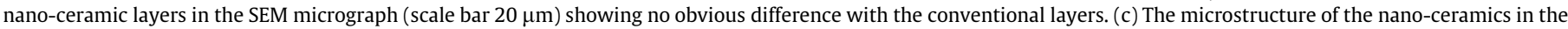
TEM micrograph (scale bar $100 \mathrm{~nm}$ ) showing the grain diameter about $40-100 \mathrm{~nm}$.

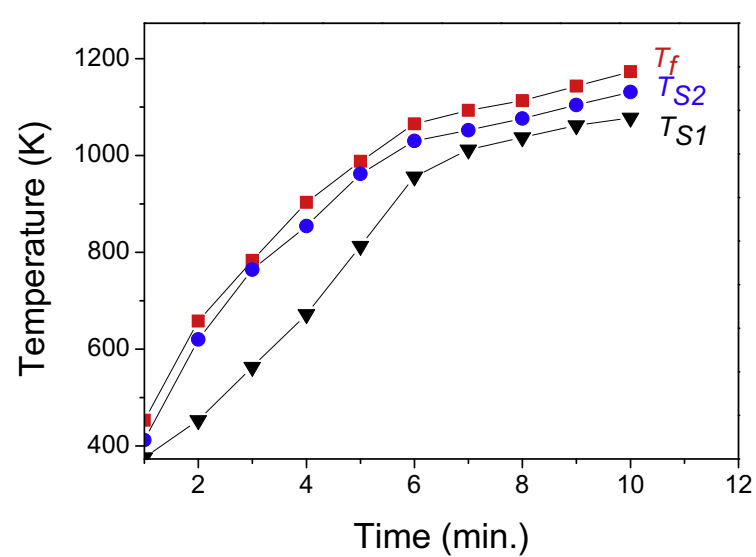

Fig. 3. The matrix temperatures of the nano-samples $\left(T_{S 1}\right)$ lower than those of the conventional ones $\left(T_{S 2}\right)$ at the same furnace temperatures $\left(T_{f}\right)$.

where the thermal conductivity $k_{m}$ of the Ni matrix is $90.7 \mathrm{~W} \mathrm{~m}^{-1}$ $\mathrm{K}^{-1}[19], k_{m}, L, L_{c}$ and $L_{m}$ for $S 1$ and $S 2$ are all same, only the thermal conductivity $k_{c}$ of the ceramic layers are different for the nanostructured and the conventional ones. Let $k_{c n}$ denote the thermal conduc- tivity of the nanostructured ceramic layers, the corresponding left side of Eq. (3) is $k_{1}, k_{c b}=2 \mathrm{~W} \mathrm{~m}^{-1} \mathrm{~K}^{-1}$ [1] denotes the thermal conductivity of the conventional ceramic layers with the micron-scale structure (i.e., the bulk structure), the corresponding left side of Eq. (3) is $k_{2}$, combining with the experimental result of $k_{1} /$ $k_{2}=0.34$, there is also $k_{c n} / k_{c b}=0.34$ approximately.

Considering that the porosity of the ceramic layers changes more or less with the change of the microstructure, the effect on the thermal conductivity, although the effect may be weak compared with the size effect of the ceramic particles when the porosity and its change are both small, was considered further. The porosity was estimated based on the image analyzing of the cross-section microstructure of the ceramic layers. The estimated porosities are $8 \%$ and $14 \%$ for the nano-ceramics and the conventional ones, respectively, which agree with the previous discussions $[20,1]$. According to the simple mixture rule, the thermal conductivity $k_{c n}\left(k_{c b}\right)$ of the ceramic layers, made of the particles and the pores, is expressed as

$K_{c n}=\left(1-f_{n}\right) k_{n}+f_{n} k_{a}$,

$K_{c b}=\left(1-f_{b}\right) k_{b}+f_{b} k_{a}$, 
Table 1

Comparison of the insulation temperatures $\left(T_{f}-T_{S i}\right)$ and the thermal conductivity between $S 1$ (nano) and $S 2$ (conventional).

\begin{tabular}{|c|c|c|c|c|c|c|c|c|c|c|}
\hline$T_{f}(\mathrm{~K})$ & 453 & 658 & 783 & 903 & 988 & 1065 & 1093 & 1113 & 1143 & 1173 \\
\hline$T_{S 2}-T_{S 1}(\mathrm{~K})$ & 36 & 167 & 201 & 182 & 149 & 74 & 40 & 39 & 42 & 53 \\
\hline$-\Delta T_{1}=T_{f}-T_{S 1}(\mathrm{~K})$ & 77 & 205 & 220 & 231 & 175 & 109 & 81 & 76 & 81 & 95 \\
\hline$-\Delta T_{2}=T_{f}-T_{S 2}(\mathrm{~K})$ & 41 & 38 & 19 & 49 & 26 & 35 & 41 & 37 & 39 & 42 \\
\hline$k_{1} / k_{2}=\Delta T_{2} / \Delta T_{1}$ & 0.53 & 0.19 & 0.09 & 0.21 & 0.15 & 0.32 & 0.51 & 0.49 & 0.48 & 0.44 \\
\hline
\end{tabular}

Table 2

Comparison of the matrix temperatures of $S 1$ (nano) and $S 3$ (without ceramics) after holding $20 \mathrm{~min}$ at the given furnace temperatures.

\begin{tabular}{lllllll}
\hline$T_{f}(\mathrm{~K})$ & 806 & 894 & 996 & 1097 & 1196 & 1294 \\
$T_{S 1}(\mathrm{~K})$ & 647 & 710 & 792 & 876 & 951 & 1017 \\
$T_{S 3}(\mathrm{~K})$ & 666 & 754 & 833 & 945 & 1060 & 1140 \\
$T_{f}-T_{S 1}(\mathrm{~K})$ & 159 & 184 & 204 & 221 & 245 & 277 \\
\hline
\end{tabular}

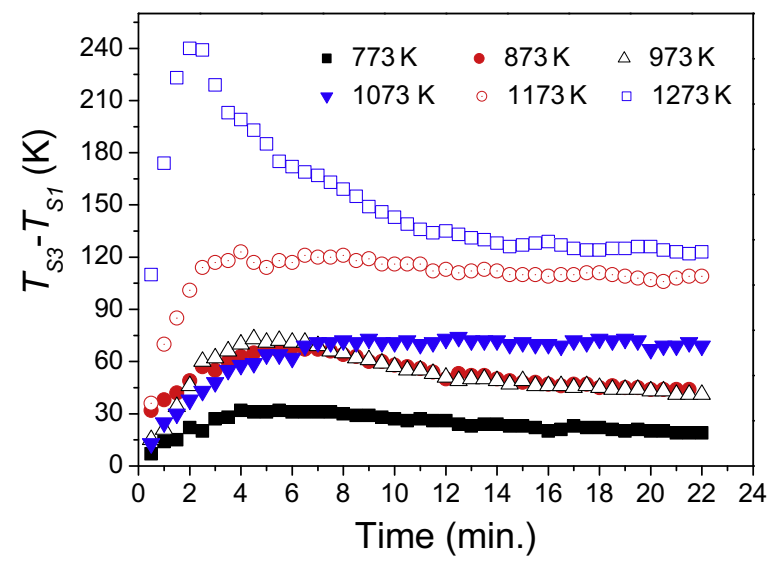

Fig. 4. Enhanced insulation temperatures $\left(T_{S 3}-T_{S 1}\right)$ of $S 1$ (nano) compared with those of $S 3$ (without ceramics) during holding temperatures.

where the porosity $f_{n}=0.08$ and $f_{b}=0.14$ for the nanostructured layers and the conventional ones, respectively, $k_{a}=0.026 \mathrm{~W} \mathrm{~m}^{-1}$ $\mathrm{K}^{-1}$ is the thermal conductivity of the air [21], $k_{n}$ and $k_{b}$ $\left(2.3 \mathrm{~W} \mathrm{~m}^{-1} \mathrm{~K}^{-1}[2]\right)$ are the thermal conductivity of the ceramic nanoparticles and the corresponding dense bulk, respectively. Combining Eqs. (4.1) and (4.2) with $k_{c n} / k_{c b}=0.34$, the pure size effect can be obtained as $k_{n} / k_{b}=0.32$, which is just in agreement with the theoretical prediction based on Eq. (1). Note that the effect of the change of the pores distribution is neglected, since the effect is weak based on the effective thermal conductivity calculation of the porous composite medium when the porosity and its change are both smaller [21].

The result indicates that the thermal conductivity of the ceramics can be reduced and the thermal insulation effect can be enhanced effectively by the nanostructurization at the given thickness and porosity, the decrease of the microstructure scale or the relatively increase of the interface roughness suppresses the phonon transport and thus the lattice thermal conductivity. In fact, the enhanced thermal shock resistance of the nanostructured ceramics has been achieved [22], which is resulted from that the nanostructure reduces the thermal conductivity, thus protects the samples during the thermal shock.

\section{Conclusion}

In summary, a size-dependent thermal conductivity model was developed to predict the ultralow thermal conductivity and the obviously improved thermal insulation effect of the nanostructured ceramic layers. According to the model, the ceramics layers made of nanograins were fabricated and the thermal insulation temperature was measured comparatively with that of the conventional ceramic layers, the agreement with the prediction was found. The designed nanostructurization based on the theory can enhance effectively thermal protection property of the coating structures and promote the application of nanomaterials in thermal barrier and energy engineering.

\section{Acknowledgements}

This work was supported by grants from the National Basic Research Programs of China (Nos. 2012CB937500 and 2010CB631206), the NSFC of China (Nos. 10802088, 10832008, 11023001, 51071164, 11021262, 91216108 and 10932011) and the opening fund of LNM. We also thank Prof. H. J. Gao for his helpful discussion.

\section{References}

[1] A.G. Evans, D.R. Mumm, J.W. Hutchinson, G.H. Meier, F.S. Pettit, Mechanism controlling the durability of thermal barrier coatings, Prog. Mater. Sci. 46 (2001) 505-553.

[2] N.P. Padture, M. Gell, E.H. Jordan, Thermal barrier coatings for gas-turbine engine applications, Science 296 (2002) 280-296.

[3] K.M. Kim, S. Shin, D.H. Lee, H.H. Cho, Influence of material properties on temperature and thermal stress of thermal barrier coating near a normal cooling hole, Int. J. Heat Mass Transfer 54 (2011) 5192-5199;

L. Yang, Y.C. Zhou, W.G. Mao, C. Lu, Real-time acoustic emission testing based on wavelet transform for the failure process of thermal barrier coatings, Appl. Phys. Lett. 93 (2008) 231906

[4] S. Raghavan, H. Wang, R.B. Dinwiddie, W.D. Porter, M.J. Mayo, The effect of grain size, porosity and yttria content on the thermal conductivity of nanocrystalline zirconia, Scr. Mater. 39 (1998) 1119-1125;

W.B. Gong, C.K. Sha, D.Q. Sun, W.Q. Wang, Microstructures and thermal insulation capability of plasma-sprayed nanostructured ceria stabilized zirconia coatings, Surf. Coat. Technol. 201 (2006) 3109-3115.

[5] J. Wu, H.B. Guo, L. Zhou, L. Wang, S.K. Gong, Microstructure and thermal properties of plasma sprayed thermal barrier coatings from nanostructured YSZ, J. Therm. Spray Tech. 19 (2010) 1186-1194;

R.S. Lima, B.R. Marple, Toward highly sintering-resistant nanostructured ZrO2$7 \mathrm{wt}$ \% 203 coatings for TBC applications by employing differential sintering, J. Therm. Spray Tech. 17 (2008) 846-852.

[6] L.H. Liang, B.W. Li, Size-dependent thermal conductivity of nanoscale semiconducting systems, Phys. Rev. B 73 (2006) 153303.

[7] Y.F. Zhu, J.S. lian, Q. Jiang, Y.F. Zhu, Modeling of the melting point, Debye temperature, thermal expansion coefficient, and the specific heat of nanostructured materials, J. Phys. Chem. C 113 (2009) 16896-16900; Y.F. Zhu, X.Y. lang, W.T. Zheng, Q. Jiang, Electron scattering and electrical conductance in polycrystalline metallic films and wires: impact of grain boundary scattering related to melting point, ACS Nano 4 (2010) 3781-3788.

[8] D. Li, Y. Wu, P. Kim, L. Shi, P.D. Yang, A. Majumdar, Thermal conductivity of individual silicon nanowires, Appl. Phys. Lett. 83 (2003) 2934-2936;

D.G. Cahill, W.K. Ford, K.E. Goodson, G.D. Mahan, A. Majumdar, H.J. Maris, R Merlin, S.R. Phillpot, Nanoscale thermal transport, J. Appl. Phys. 93 (2003) 793818.

[9] B. Qiu, L. Sun, X.L. Ruan, Lattice thermal conductivity reduction in $\mathrm{Bi}_{2} \mathrm{Te}_{3}$ quantum wires with smooth and rough surfaces: a molecular dynamics study, Phys. Rev. B 83 (2011) 035312;

V. Samvedi, V. Tomar, The role of straining and morphology in thermal conductivity of a set of $\mathrm{Si}-\mathrm{Ge}$ superlattices and biomimetic $\mathrm{Si}-\mathrm{Ge}$ nanocomposites, J. Phys. D: Appl. Phys. 43 (2010) 135401.

[10] Q. Jiang, H.X. Shi, M. Zhao, Melting thermodynamics of organic nanocrystals, J. Chem. Phys. 111 (1999) 2176-2180.

[11] D.C. Jia, Ceramic Materials 2nd (Chinese), in: Y. Zhou (Ed.), Science Publisher, Beijing, 2004, p. 320.

[12] A.L. Ortiz, J. Sánchez-González, L.M. González-Méndez, F.L. Cumbrera, Determination of the thermal stability and isothermal bulk modulus of the $\mathrm{ZrO}_{2}$ polymorphs at room temperature by molecular dynamics with a semiempirical quantum-chemical model, Ceram. Int. 33 (2007) 705-709. 
[13] X.W. Song, M. Xie, S.L. An, X.H. Hao, R.D. Mu, Structure and thermal properties of $\mathrm{ZrO}_{2}-\mathrm{Ta}_{2} \mathrm{O}_{5}-\mathrm{Y}_{2} \mathrm{O}_{3}-\mathrm{Ln}_{2} \mathrm{O}_{3}$ ( $\mathrm{Ln}=\mathrm{Nd}$, Sm or $\mathrm{Gd}$ ) ceramics for thermal barrier coatings, Scr. Mater. 62 (2010) 879-882.

[14] Y.F. Zhu, J.S. Lian, Q. Jiang, Re-examination of Casimir limit for phonon traveling in semiconductor nanostructures, Appl. Phys. Lett. 92 (2008) 113101.

[15] Z. Chen, R.W. Trice, M. Besser, X. Yang, D. Sordelet, Air-plasma spraying colloidal solutions of nanosized ceramic powders, J. Mater. Sci. 39 (2004) 4171-4178.

[16] B.W. Li, G. Casati, J. Wang, T. Prosen, Fourier law in the alternate-mass hardcore potential chain, Phys. Rev. Lett. 92 (2004) 254301;

N. Yang, G. Zhang, B.W. Li, Ultralow thermal conductivity of isotope-doped silicon nanowires, Nano Lett. 8 (2008) 276-280.

[17] C. Hu, M. Mongen, P.S. Ho, A. Jain, W.N. Gill, J.L. Plawsky, P.C. Wayner, Thermal conductivity study of porous low-k dielectric materials, Appl. Phys. Lett. 77 (2000) 145-147.
[18] L.H. Liang, Y.G. Wei, B.W. Li, Size-dependent interface phonon transmission and thermal conductivity of nanolaminates, J. Appl. Phys. 103 (2008) 084314

[19] Sargent-Welch Scientific Company, Periodic Table of the Elements Skokie Illinois, 1980, p. 1

[20] R.S. Lima, B.R. Marple, Nanostructured YSZ thermal barrier coating engineered to counteract sintering effects, Mater. Sci. Eng. A 485 (2008) 182-193.

[21] L.H. Liang, Y.G. Wei, B.W. Li, Thermal conductivity of composites with nanoscale inclusions and size-dependent percolation, J. Phys.: Condens. Matter 20 (2008) 365201.

[22] B. Liang, C.X. Ding, Thermal shock resistances of nanostructured and conventional zirconia coatings deposited by atmospheric plasma spraying, Surf. Coat. Technol. 197 (2005) 185-192;

F. Song, S.H. Meng, X.H. Xu, Y.F. Shao, Enhanced thermal shock resistance of ceramics through biomimetically inspired nanofins, Phys. Rev. Lett. 104 (2010) 125502. 